\title{
Teaching medical applications and workflow of three-dimensional printing to medical students: Results of a pilot elective course
}

\author{
Jarosław Meyer-Szary, Agastya Patel@, Marlon Souza Luis, \\ Robert Sabiniewicz, Joanna Kwiatkowska \\ Department of Pediatric Cardiology and Congenital Heart Defects, \\ Medical University of Gdansk, Poland
}

Three-dimensional printing (3Dp) employs a process of placing layers upon layers of material to create a physical object based on a digitally designed model [1]. The process (workflow) of making 3D models involves data acquisition from two-dimensional (2D) images, virtual reconstruction and physical printing [1]. 3Dp models are sought as an effective means for educating not only medical students, but also physicians, residents, nurses and other healthcare providers, as well as an aid in planning and training (simulating) procedures [2-8]. Having had experience in the field and seeing the increasing interest, as depicted by a growing body of literature, in medical 3Dp leads to a question of whether it is worthwhile and possible to teach undergraduate medical students about the basics of 3Dp workflow within a reasonably short timeframe. For this purpose, a pilot hands-on $3 \mathrm{Dp}$ elective course was organized to expose medical students to the potential of 3Dp in the hopes of raising their awareness and interest in the concept.

The course was comprised of 15 teaching hours, equally divided into 5 days. The first 3 days of the course included seminars on the following topics - medical applications of 3Dp (with examples from experience and published literature); available software, printing technologies and materials; and overview of the $3 \mathrm{Dp}$ workflow. The seminars were given by a pediatric cardiologist with experience in medical 3Dp and representatives of Zortrax and Sinterit, well-known as desktop 3D-printer manufacturing companies. During the seminars, students asked questions and actively participated in discussion. The last 2 days consisted of handson workshops, wherein students worked in pairs on four computed tomography (CT) scans to prepare models of scapula, middle aortic syndrome, vascular ring and trachea, and coronary arteries, respectively. On the first day of the workshop, the students were taught how to segment the region of interest from the 2D images, create a digital 3D model and inspect them for artifacts, which were fixed if present. Each pair practiced these steps on all four CT scans using Materialise Mimics Innovation Suite 22.0. The students then prepared a STL file for the vascular ring and trachea model, which was printed overnight for the second workshop day. On the last day, the students were taught how to post-process the printed 3D model (e.g. removing support structures). Each pair worked together on their models to prepare the final product, which they were allowed to take home.

Fourteen $4^{\text {th }}$ and $5^{\text {th }}$ year medical students from the Medical University of Gdansk participated in this pilot course. The enrollment for the course was done through an online system on a "first-come, first-served" basis. Ten students were eligible to take part in the study — three had prior experience in making $3 \mathrm{Dp}$ models and one did not consent to take part in the study. To gauge the effectiveness of the course, a questionnaire and a technical test was developed which the students filled out prior to entering and after completing the course. The entry questionnaire consisted of 22 Likert scale items assessing their familiarity with $3 \mathrm{Dp}$, their opinion on its applications and their perception of

Address for correspondence: Agastya Patel, Department of Pediatric Cardiology and Congenital Heart Defects, Medical University of Gdansk, ul. M. Skłodowskiej-Curie 3a, 80-211, Gdańsk, Poland, tel: +48 583492882 , e-mail: agastyap24@gmail.com

Received: 13.03.2020 Accepted: 21.07.2020 
Table 1. Results of entry- and exit-subjective questionnaire and objective technical test scores.

\begin{tabular}{|c|c|c|c|}
\hline & $\begin{array}{l}\text { Entry-responses } \\
\qquad(\mathrm{n}=10) \\
\text { Median (IQR) }\end{array}$ & $\begin{array}{l}\text { Exit-response } \\
\qquad(\mathrm{n}=10) \\
\text { Median (IQR) }\end{array}$ & $\mathbf{P}$ \\
\hline $\begin{array}{l}\text { 3Dp models are accurate and precise representation } \\
\text { of patient's anatomy }\end{array}$ & $3(2.75-4)$ & $4(3.75-5)$ & 0.02 \\
\hline $\begin{array}{l}\text { Working through the process of making } 3 \mathrm{Dp} \text { models } \\
\text { would improve my understanding of anatomy }\end{array}$ & $4.5(3-5)$ & $5(4.75-5)$ & 0.18 \\
\hline $\begin{array}{l}\text { 3D printing helps in understanding pathologies and } \\
\text { planning medical interventions }\end{array}$ & $4(3.75-4.25)$ & $5(4.75-5)$ & 0.01 \\
\hline $\begin{array}{l}\text { 3Dp models can be used to plan, prepare and practice } \\
\text { surgical procedures }\end{array}$ & $4(3-5)$ & $5(4-5)$ & 0.22 \\
\hline 3D printing has a role in medical education & $4.5(4-5)$ & $5(4-5)$ & 0.75 \\
\hline $\begin{array}{l}\text { 3D printing can be used to make customized prothesis } \\
\text { and implants }\end{array}$ & $5(4-5)$ & $5(4-5)$ & 0.75 \\
\hline $\begin{array}{l}\text { 3Dp models can be used to educate patients about } \\
\text { their diseases and treatment }\end{array}$ & $4(3-5)$ & $5(5-5)$ & 0.03 \\
\hline $\begin{array}{l}\text { 3D printing can be used in pharmaceutical research } \\
\text { (e.g. drug dosages, delivery system }\end{array}$ & $3(2-3)$ & $4(3-5)$ & 0.02 \\
\hline $\begin{array}{l}\text { 3Dp models can be used in administering doses of } \\
\text { radiotherapy in treatment of superficial cancers }\end{array}$ & $3(2-3)$ & $3.5(2-4.25)$ & 0.34 \\
\hline $\begin{array}{l}\text { 3D printing can be currently used to make organs for } \\
\text { transplantation }\end{array}$ & $2(2-3.25)$ & $2.5(1-5)$ & 0.35 \\
\hline $\begin{array}{l}\text { 3Dp models can be used to make physical libraries of } \\
\text { several pathologies and their variants }\end{array}$ & $4(3-5)$ & $5(4.75-5)$ & 0.38 \\
\hline $\begin{array}{l}\text { 3D printing is a widely researched concept in medicine } \\
\text { and healthcare }\end{array}$ & $3(2-3)$ & $5(2.75-5)$ & 0.03 \\
\hline Senior doctors can benefit from 3Dp models & $5(3.75-5)$ & $5(4-5)$ & 0.63 \\
\hline Medical residents can benefit from 3Dp models & $5(3-5)$ & $5(5-5)$ & 0.5 \\
\hline Medical students can benefit from 3Dp models & $5(3-5)$ & $5(5-5)$ & 0.13 \\
\hline Nurses can benefit from 3Dp models & $4(3-5)$ & $5(4.75-5)$ & 0.13 \\
\hline Patients can benefit from 3Dp models & $4.5(4-5)$ & $5(5-5)$ & 0.06 \\
\hline $3 \mathrm{D}$ printing models is an extremely time consuming & $4.5(3-5)$ & $5(3.75-5)$ & 0.19 \\
\hline $3 \mathrm{D}$ printing models is a very costly process & $3(3-5)$ & $4(2.75-4.25)$ & $>0.99$ \\
\hline $\begin{array}{l}\text { The process of printing 3D models is difficult. } \\
\text { It requires a lot of skill and experience }\end{array}$ & $3(3-4.25)$ & $3(2-4)$ & 0.23 \\
\hline $\begin{array}{l}\text { It is possible to customize 3D printed models after they } \\
\text { are printed (e.g. adding colors, textures, labels etc.) }\end{array}$ & $4(2.75-5)$ & $4.5(3.75-5)$ & 0.19 \\
\hline Technical Test Scores* & $6.3 \pm 1.34$ & $8.4 \pm 1.65$ & 0.0049 \\
\hline
\end{tabular}
range

creating 3Dp models. In the exit questionnaire, the students were asked about which step of the $3 \mathrm{Dp}$ workflow was the most challenging for them and to give their opinion on how the course may have influenced their medical education. It included 6 Likert scale items regarding the content and quality of the course. The technical test included 7 true/false and 1 open question along with a question regarding the order of steps in 3Dp workflow. A statistical analysis of the questionnaire responses and test scores was performed using the Wilcoxon test and Paired T-test with GraphPad Prism 8.0. As indicators of significance, two-tailed p-values of $<0.05$ was used.

Prior to starting the course, $70 \%$ of the students stated that they were "somewhat familiar" with the concept of $3 \mathrm{Dp}$. In comparison, $40 \%$ believed that they "have experience" and $60 \%$ were "somewhat familiar" at the end of the course (Suppl. Fig. 1A). The course was able to positively change the opinion of the students regarding the following medical applications of 3Dp - creating 
accurate representations of a specific patient's anatomy $(\mathrm{p}=0.02)$, helpful in understanding pathologies and planning medical interventions $(p=0.01)$, beneficial for patient education $(p=0.03)$ and application in pharmaceutical research $(p=0.02)$ (Table 1). After the course, they also realized the scientific interest in researching the concept of $3 \mathrm{Dp}$ in the field of medicine $(\mathrm{p}=0.03)$. In both entry and exit responses, the students unanimously agreed that $3 \mathrm{Dp}$ has a role in medical education, making customized protheses, and practicing surgical procedures. At the end of the course, $40 \%$ of students disagreed that 3Dp is difficult and requires experience as compared to $0 \%$ before the course (Suppl. Fig. 1B).

Majority (60\%) of the students found segmentation to be the most challenging step in the $3 \mathrm{Dp}$ workflow, the rest found analyzing the CT images, inspecting the digital model and preparing the model for printing to be more challenging (Suppl. Fig. 1C). All students were pleased with the content and methods of teaching 3Dp used in the course (Suppl. Fig. 1D). Every student stated that they would be interested in participating in such courses in the future and would recommend them to fellow students (Suppl. Fig. 1D). It was also seen that learning the process of 3Dp and its application had a positive impact on the experience of learning medicine of each student participating in the course (Suppl. Fig. 1D). The students scored significantly higher in the technical exit test (mean score $=8.4$ vs. $6.3, p=0.005)$. Majority $(60 \%)$ of students were able to correctly arrange the steps of the 3Dp workflow in the exit test as compared to only $30 \%$ in the entry test (Suppl. Fig. 1E).

Three-dimensional printing is a relatively novel and emerging concept in the field of medicine with widespread applications. It is therefore worthwhile introducing undergraduate medical students to, not only its uses but also the process of creating 3 Dp models. The present study demonstrates that the course including hands-on workshops such as these are effective for this purpose. Learning and experiencing 3Dp workflow adds an additional skill to the repertoire of a student while also enhancing their medical education. Courses like these have the potential of raising interest and attracting students to partake and contribute in furthering the practice of medical 3Dp.

\section{Conflict of interest: None declared}

\section{References}

1. Luo H, Meyer-Szary J, Wang Z, et al. Three-dimensional printing in cardiology: Current applications and future challenges. Cardiol J. 2017; 24(4): 436-444, doi: 10.5603/CJ.a2017.0056, indexed in Pubmed: 28541602.

2. Chen S, Pan Z, Wu Y, et al. The role of three-dimensional printed models of skull in anatomy education: a randomized controlled trail. Sci Rep. 2017; 7(1): 575, doi: 10.1038/s41598-017-00647-1, indexed in Pubmed: 28373643.

3. Wang L, Ye X, Hao Q, et al. Three-dimensional intracranial middle cerebral artery aneurysm models for aneurysm surgery and training. J Clin Neurosci. 2018; 50: 77-82, doi: 10.1016/j. jocn.2018.01.074, indexed in Pubmed: 29439905.

4. Wake N, Rosenkrantz AB, Huang R, et al. Patient-specific 3D printed and augmented reality kidney and prostate cancer models: impact on patient education. 3D Print Med. 2019; 5(1): 4, doi: 10.1186/s41205-019-0041-3, indexed in Pubmed: 30783869.

5. Olivieri LJ, Su L, Hynes CF, et al. „Just-In-Time” Simulation Training Using 3-D Printed Cardiac Models After Congenital Cardiac Surgery. World J Pediatr Congenit Heart Surg. 2016; 7(2): 164-168, doi: 10.1177/2150135115623961, indexed in Pubmed: 26957398.

6. Biglino G, Capelli C, Koniordou D, et al. Use of 3D models of congenital heart disease as an education tool for cardiac nurses. Congenit Heart Dis. 2017; 12(1): 113-118, doi: 10.1111/chd.12414, indexed in Pubmed: 27666734.

7. Meyer-Szary J, Woźniak-Mielczarek L, Sabiniewicz D, et al. Feasibility of in-house rapid prototyping of cardiovascular threedimensional models for planning and training non-standard interventional procedures. Cardiol J. 2019; 26(6): 790-792, doi: 10.5603/CJ.2019.0115, indexed in Pubmed: 31970736.

8. Sabiniewicz R, Meyer-Szary J, Potaż P, et al. Melody valve implantation pre-procedural planning using custom-made $3 \mathrm{D}$ printed model of the region of interest. Adv Interv Cardiol. 2018; 14(2): 210-211, doi: 10.5114/aic.2018.76419, indexed in Pubmed: 30008780 . 